\title{
BMJ Open The temporal association of excessive health expenditure with suicidal ideation among primary income earners: a cross-sectional design using the Korean Welfare Panel Survey (KoWePS)
}

\author{
Jaeyong Shin, ${ }^{1,2,3,{ }^{*}}$ Jae Woo Choi, ${ }^{1,2,{ }^{*}}$ Sung-in Jang, ${ }^{1,2,3}$ Young Choi, ${ }^{1,2}$ \\ Sang Gyu Lee, ${ }^{4}$ Tae Hwan Ihm, ${ }^{5}$ Eun-Cheol Park ${ }^{2,3}$
}

To cite: Shin J, Choi JW, Jang S-in, et al. The temporal association of excessive health expenditure with suicidal ideation among primary income earners: a cross-sectional design using the Korean Welfare Panel Survey (KoWePS). BMJ Open 2015:5: 007421.

doi:10.1136/bmjopen-2014007421

- Prepublication history and additional material is available. To view please visit the journal (http://dx.doi.org/ 10.1136/bmjopen-2014007421)

*JS and JWC are co-first authors.

Received 19 December 2014 Revised 19 May 2015 Accepted 22 May 2015

CrossMark

For numbered affiliations see end of article.

Correspondence to Dr Eun-Cheol Park; ecpark@yuhs.ac

\section{ABSTRACT}

Objective: Excessive health expenditure (EHE) is a global issue for households suffering from high-cost medical conditions, low incomes and limited insurance coverage. After the international financial crisis of 2008, EHE became a social problem in developed countries. Such economic crisis might induce severe mental stress, resulting in suicidal ideation.

Methods: We used the Korean Welfare Panel Study (KoWePS) from 2011 to 2013 and selected primary income earners, who were defined as practical and economic representatives of households; the total number of analysed samples was 4247 of 5717 households in the database. We only included households that had never experienced EHE before 2011. To examine the temporal relationship between EHE and suicidal ideation, we conducted a logistic regression analysis.

Results: Among 4247 participants, 146 (3.4\%) experienced suicidal ideation, whereas $4101(96.6 \%)$ did not. One scale of depression score $(\mathrm{OR}=1.28, \mathrm{Cl}$ 1.23 to $1.34, p<0.001$ ) was associated with increased suicidal ideation. Such ideation was influenced to a greater extent by a recent EHE above $10 \%$ of disposable income (OR=1.91, Cl 1.16 to 3.15 , $p=0.012)$ than by either a remote EHE $(O R=1.29, \mathrm{Cl}$ 0.71 to 2.32) or one in 2011 and $2012(\mathrm{OR}=1.67, \mathrm{Cl}$ 1.01 to $2.78, p=0.048$ ).

Conclusions: In this study, more recent EHE resulted in more suicidal ideation. In conclusion, we suggest that recent household EHE might be considered as an important factor to prevent suicidal ideation and to improve the mental health of individuals.

\section{INTRODUCTION}

According to the Organisation for Economic Co-operation and Development (OECD) health statistics data, the age-standardised

\section{Strengths and limitations of this study}

- We used the representative national data 'Korea Welfare Panel Study (KoWePS)' from the national research institute, 'Korea Institute for Health and Social Affairs, KIHASA'.

- We divided the occurrences of excessive health expenditure into four subgroups (none, recent, remote and both years) in an attempt to analyse temporal causality.

- We could not determine casual relationships due to the cross-sectional nature of this study.

- Since the number of suicide attempts observed during the study period was too small to continue the analysis, we used suicidal ideation as a dependent variable.

- The number of cases of suicidal ideation may have been too small to determine all the associations.

suicide mortality rate in 2011 was 33.3 per 100000 individuals. ${ }^{12}$ Among all OECD countries, this is the highest value, while the rate of increase in suicidal mortality remains constant. Since financial stress might be an important factor in Korea, we have to place concern on the financially vulnerable groups, such as primary income earners with excessive health expenditure (EHE) in a household.

Protection from EHE is widely regarded as a desirable objective of healthcare systems and policies. ${ }^{3-7}$ However, EHE is not always the same as high healthcare cost. For example, an expensive surgery might not be excessive if a household does not bear its full cost, because the service is provided free or at a subsidised fee, or is covered by thirdparty insurance. On the other hand, even 
the small cost of common illnesses can be financially disastrous for poor households with no insurance.

Although EHE is usually defined as catastrophic health expenditure, health-related expenses over $40 \%$ of disposable income per annum according to $\mathrm{WHO},{ }^{3}$ it has often been defined differently by various studies. ${ }^{8-10}$ Thus, in this study, we defined different cut-off values as $10 \%, 20 \%$ and $40 \%$ to enhance the effectiveness of the study design.

According to OECD health data, patients pay the highest percentage of their medical fees $(>35 \%)$ out of pocket in the Republic of Korea. ${ }^{11}$ As the primary function of insurance is to protect the patient from harm in terms of health and economic risk, it is critical to reduce the occurrences of EHE. According to Korean National Statistics, the number of households experiencing EHE of more than $40 \%$ of disposable household income in 2010 was 618000 , or $3.9 \%$ of all households. This figure was only $1 \%$ in 2002 , but began to increase thereafter, reaching $3.3 \%$ by $2006 .{ }^{1}$ These data suggest that Koreans are at risk of occurrences of EHE. Thus, they might be vulnerable to a decline in their economic welfare in the face of ill health, especially when EHEs exist.

For example, in 2008, the state of Oregon, in the USA, initiated a limited expansion of its Medicaid programme for low-income adults. ${ }^{12}$ Medicaid coverage decreased the probability of a positive screening for depression ( -9.15 percentage points; $95 \%$ CI -16.70 to $-1.60 ; \mathrm{p}=0.02)$, increased the use of many preventive services and nearly eliminated excessive out-of-pocket medical expenditures. This study showed that mental health could be improved by reducing the financial burden for health.

Another study, which observed the association between EHE and depression, was conducted in India. ${ }^{13}$ According to this cross-sectional study in Goa, India, depressive disorder was associated with significantly higher healthcare costs, lost time costs and risk of EHE. There was a linear association between psychological morbidity scores and the risk of EHE. From this study, it could be suggested that economic arguments due to health problems were considered to be a key driver of mental health policy.

Although few studies on EHE in Korea were published in Korea, ${ }^{14}{ }^{15}$ there were no appropriate study designs to examine the association between EHEs and mental health.

The aims of this study were to: (1) compare health expenditures between households with and without EHEs; (2) examine the temporal association between EHEs and suicidal ideation among the primary income earners in households and (3) test whether recent EHEs have a greater impact on suicidal ideation than more remote EHEs.

\section{METHODS}

Participants

Data from the Korean Welfare Panel Study (KoWePS: Korea Institute for Health \& Social Affairs \& Seoul
National University Social Welfare Research Center, 2008) from 2011 to 2013, were obtained for this study. The KoWePS is an ongoing longitudinal study of a nationally representative sample of Korean households that collects data annually. The KoWePS-led survey population represents $90 \%$ of the census conducted in 2005 . Statisticians of this survey determined final panel households by applying a 'Stratified Double Sampling' model. The constituent questionnaires in this survey consisted of a household member survey for household members aged 15 years and over, a household survey and a supplementary survey for special topics. Face-to-face interviews were used to gain information during the first year of the study.

This study respected the provisions of the Declaration of Helsinki for ethical medical research. Since this study used secondary data from the Korea Institute for Health and Social Welfare, we did not need to obtain individual informed consent. All patient records/information in this study were anonymised and de-identified prior to analysis. In addition, we were granted the approval of the institutional review board at the graduate school of public health in Yonsei University (Institutional Review Board approval number 2-1040939-AB-N-01-2015-202).

We especially focused on the suicidal ideation of household heads, who are defined as the primary income earners and practical representatives of the household. The study suggests that the most vulnerable family member to an economic crisis might be a primary income earner. Hence, primary income earners were selected for the questionnaire. The total number of analysed samples was 4247 of 5717 households from the database. In Korea, there were a total 17339422 households enrolled in a governmental system in 2010. We only included households that had never experienced EHE before 2011, and never missed any annual surveys during the study period.

\section{Covariates of individual and household characteristics}

In this study, we used several covariates to control for demographic and socioeconomic characteristics of individual levels. Demographic characteristics such as sex, age, educational level, marital status, perceived heath status, regular medication more than 3 months and depressive mood status were included. Since the official age of retirement in Korea is 65 years, we divided the age groups into one group under 65 years, and another at 65 years and over. Four education categories including degree from elementary, middle, high school, and college and above, were self-reported by participants. We divided perceived health status with three categories into good, normal and bad, while the original survey questionnaire used a scale with five degrees including excellent, good, normal, bad and very bad. The question of self-rated health is as follows: 'How would you rate your general health during the last year?'. In terms of regular medication, interviewers asked whether the participants were taking any medication regularly for more 
than the last 3 months or not. This was used as an indicator to determine presence of any kind of chronic diseases.

We also considered other covariates of households, such as number of family members, economically active family members, disabled members and members over 65 years of age. An economically active member was defined as someone who worked regularly and earned a salary during the last 1 year. The disabled were those officially diagnosed by doctors using the standard of the national guideline for the disabled.

\section{EHE as an interesting variable}

We defined EHE as the health expenditure over $10 \%$ of disposable income, which is the standard threshold from the Ministry of Health and Welfare, South Korea. Furthermore, to examine the increased relationship between EHE and suicidal ideation, we also performed another analysis using various cut-off values as $20 \%$ and $40 \%$ for EHE, the latter being the WHO standard.

The household questionnaire portion of the KoWePS included a set of questions that asked about the income of all household members. These questions addressed earned income, income from assets and miscellaneous income. The present study utilised this set of incomerelated questions to create total household income and disposable income variable. To obtain the number of households experiencing EHE, we divided the total cost of health expenditures into disposable income for each household. Moreover, we considered temporal factors of EHE. In other words, we determined when an excessive event occurred: none, remote (in 2011), recent (in 2012), and in both 2011 and 2012.

\section{Measuring depressive symptoms and suicidal ideation}

To measure the level of depression, the Center for Epidemiologic Studies Depression scale (CESD) was used, which was originally designed to measure depressive symptoms in the general population, ${ }^{16}$ and has been widely used in community and clinically based samples. ${ }^{17} 18$ For each year of the study period, the respondents reported symptoms experienced during the previous week using a four-point scale. Depression scores for each year were calculated by totalling across 11 items.

Suicidal ideation was assessed by a questionnaire regarding the occurrence of suicidal ideation during the past year as follows: 'Have you seriously considered suicide at any time in the past year?'.

\section{Statistical analysis}

The frequency of EHE for samples stratified by demographic and socioeconomic status was determined by performing a $\chi^{2}$ test. To examine the relationship between EHE and suicidal ideation, we conducted a logistic regression analysis.

In logistic regression analysis, model 1 includes individual level variables. Furthermore, variables in model 2 are extended to both individual and household levels. When $p$ value was less than 0.05 , we defined the statistical result as significant. We used the SAS V.9.3 statistical package (Cary, North Carolina, USA) for statistical analysis.

\section{RESULTS}

The general characteristics of primary income earners and households are shown in table 1. A total of 4247 households are enrolled in this study. Among them, 146 heads of households $(3.4 \%)$ reported suicidal ideation once or more during the past year, whereas 4101 $(96.6 \%)$ did not. A total number of 76 men $(52.1 \%)$ and 70 women $(47.9 \%)$ had suicidal ideation among primary income earners. Moreover, the lowest educated participants with elementary level of education, 65 participants $(44.5 \%)$, had a higher proportion among the group with suicidal ideation.

Thresholds of EHE of $10 \%$ and $40 \%$ above disposable income are significantly different for those who did and did not have suicidal ideation (table 2). Among 875 participants whose households suffered from EHE of over $10 \%$ during the last two consecutive years, 49 persons (5.6\%) experienced suicidal ideation. In 62 participants with EHE above $40 \%$ during the last two consecutive years, eight persons $(12.9 \%)$ reported suicidal ideation.

We carried out multivariate analyses using a logistic regression model based on the threshold of EHE above $10 \%$ of disposable income (table 3 ). In model 1 , the primary income earners who had poor perceived health status (OR=1.78, 95\% CI 1.03 to 3.08) and a higher depression score (CESD-11, OR=1.29, 95\% CI 1.24 to $1.35)$ are more vulnerable to suicidal ideation. In model 2, a higher depressive score (CESD-11, OR $=1.28,95 \%$ CI 1.23 to 1.34 ) is associated with the presence of suicidal ideation. In both models 1 and 2, EHE occurring in 2012 (model 1; OR=2.03, 95\% CI 1.23 to $3.35 /$ model 2; OR=1.91, 95\% CI 1.16 to 3.15) and for both consecutive years in 2011 and 2012 (model 1; OR=1.83, 95\% CI 1.12 to 2.98 /model 2 ; OR=1.67, $95 \%$ CI 1.01 to 2.78 ) have statistically significant ORs for suicidal ideation. Moreover, the suicidal ideation is influenced to a greater extent by a recent EHE than by a remote EHE or EHE in both years. To compare the fitness between the models, we used $-2 \operatorname{logL}$ methods. Through this measurement, it appears that model 2 is more suitable for suicidal ideation because it has a lower -2logL than model 1 .

Although the official cut-off value in our study is $10 \%$, we also tested with other values as cut-off thresholds. These results showed that primary income earners are more vulnerable to the high threshold of EHE. When EHE is above $20 \%$, compared with $10 \%$, the ORs of suicidal ideation associated with EHE was increased in the recent year (figure 1).

For EHE above $40 \%$ of disposable income, the consecutive 2 years with EHE is statistically significantly correlated with a higher rate of suicidal ideation (model 2; 
Table 1 Demographic characteristics among participants based on the presence of suicidal ideation in heads of households

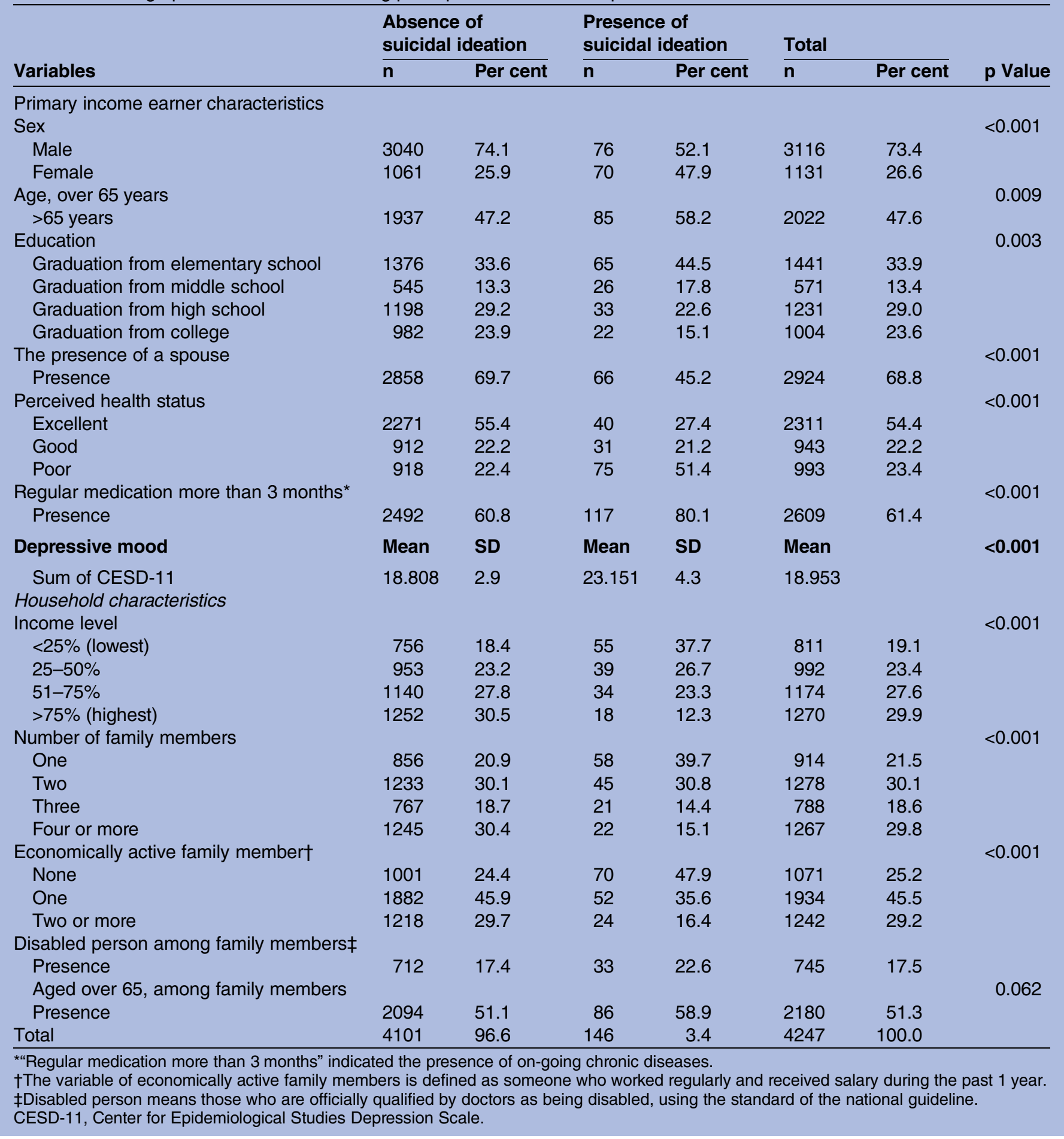

$\mathrm{OR}=2.67,95 \%$ CI 1.10 to 6.46 ) (see online supplementary table $\mathrm{S} 1$ ).

Since the heads of households with depressive symptoms may have more correlation with suicidal ideation, a subgroup analysis was performed for the primary income earners whose sum of CESD-11 score was 16 or more (table 4). A sum of CESD-11 score of over 16 indicates potential risk for major depressive disorder (MDD). In this subgroup analysis, the primary income earners were more vulnerable to the higher EHE. In other words, when EHE was above $20 \%$ (in 2012; $\mathrm{OR}=2.46,95 \%$ CI 1.57 to 3.85/in both 2011 and 2012; $\mathrm{OR}=1.89$, 95\% CI 1.08 to 3.31 ) compared to $10 \%$ (in 2012; $\mathrm{OR}=1.98,95 \%$ CI 1.21 to 3.22 /in both 2011 and 2012; $\mathrm{OR}=1.86$, $95 \%$ CI 1.15 to 3.02 ), suicidal ideation was increased.

According to subgroup analysis by sex in 2012, women primary income earners with recent EHEs are more vulnerable to suicidal ideation (EHE $>10 \%$; OR=2.71, 95\% CI 1.25 to $5.86 / \mathrm{EHE}>20 \%$; OR=2.66, $95 \%$ CI 1.37 to 
Table 2 Bivariate analysis, based on the presence of suicidal ideation in heads of households and the occurrence of excessive health expenditures during the past 2 years

\begin{tabular}{|c|c|c|c|c|c|c|c|c|c|c|c|c|}
\hline \multirow{3}{*}{$\begin{array}{l}\text { The occurrence of } \\
\text { excessive health } \\
\text { expenditure during } \\
\text { the past } 2 \text { years }\end{array}$} & \multicolumn{6}{|c|}{ Excessive health expenditure $>10 \%$ * } & \multicolumn{6}{|c|}{ Excessive health expenditure $>40 \%{ }^{\star \star}$} \\
\hline & \multicolumn{2}{|c|}{$\begin{array}{l}\text { Absence of } \\
\text { suicidal } \\
\text { ideation }\end{array}$} & \multicolumn{2}{|c|}{$\begin{array}{l}\text { Presence } \\
\text { of suicidal } \\
\text { ideation }\end{array}$} & \multirow[b]{2}{*}{ Total } & \multirow[b]{2}{*}{ p Value } & \multicolumn{2}{|c|}{$\begin{array}{l}\text { Absence of } \\
\text { suicidal } \\
\text { ideation }\end{array}$} & \multicolumn{2}{|c|}{$\begin{array}{l}\text { Presence } \\
\text { of suicidal } \\
\text { ideation }\end{array}$} & \multirow[b]{2}{*}{ Total } & \multirow[b]{2}{*}{ p Value } \\
\hline & $\mathbf{n}$ & $\begin{array}{l}\text { Per } \\
\text { cent }\end{array}$ & $\mathbf{N}$ & $\begin{array}{l}\text { Per } \\
\text { cent }\end{array}$ & & & $\mathbf{n}$ & $\begin{array}{l}\text { Per } \\
\text { cent }\end{array}$ & $\mathbf{n}$ & $\begin{array}{l}\text { Per } \\
\text { cent }\end{array}$ & & \\
\hline None & 2061 & 98.0 & 43 & 2.0 & 2104 & $<0.001$ & 3683 & 97.0 & 115 & 3.0 & 3798 & $<0.001$ \\
\hline 2011, remote & 582 & 96.8 & 19 & 3.2 & 601 & & 180 & 94.7 & 10 & 5.3 & 190 & \\
\hline 2012 , recent & 632 & 94.8 & 35 & 5.2 & 667 & & 184 & 93.4 & 13 & 6.6 & 197 & \\
\hline 2011 and 2012 & 826 & 94.4 & 49 & 5.6 & 875 & & 54 & 87.1 & 8 & 12.9 & 62 & \\
\hline Total & 4101 & 96.6 & 146 & 3.4 & 4247 & & 4101 & 96.6 & 146 & 3.4 & 4247 & \\
\hline
\end{tabular}

The threshold of $10 \%^{*}$ as excessive health expenditure is the standard from the Ministry of Health and Welfare in Korea, while that of $40 \%{ }^{* *}$ is from WHO. As WHO recommended using flexible threshold according to cultural and national background differently, we performed further statistical analysis using $10 \%$ on paper, although we also performed another statistical analysis in online supplementary materials.

5.15) than the reference group without any EHE history (see online supplementary table S2). Although men do not have statistically meaningful ORs, the male participants with EHE above $10 \%$, and $20 \%$ above in the recent 1 year, had higher values for suicidal ideation than the reference group without any EHE history during the last 2 years.

\section{DISCUSSION}

According to measurements of the temporal association with EHE during 2011 and 2012, 2012 had meaningful increases in ORs for suicidal ideation among those with EHE above $10 \%$. We also performed a subgroup analysis for primary income earners with potential risk of MDD. The temporal relationship between EHE and suicidal ideation is stronger in this potentially depressed group than in the others. Within this group, the participants with EHE over $20 \%$ showed a higher OR than 1 of EHE over $10 \%$. Interestingly, in EHE over $40 \%$, in 2012, 1 year is not statically associated with suicidal ideation. However, the two consecutive 2 years with EHE are highly associated with suicidal ideation. Since the number of households with EHE over $40 \%$ is only 197 (4.4\%), the OR of 2012 might not show statistically increased OR for suicidal ideation. In spite of this limited condition, the consecutive occurrence of EHE has strong statistical association with suicidal ideation. Thus, we need to focus on the households with EHE in a long term through appropriate intervention based on social consensus.

In addition, when the primary income earners in households are women, EHE is more associated with suicidal ideation. Even though we need some further investigation to reveal the exact mechanism of gender difference, we suggest that the job insecurity of women and surplus financial stress to caregiving might induce more suicidal ideation compared with men. According to the study in France, people with unstable and unfavourable employment characteristics are disproportionately likely to have suicidal ideation. ${ }^{19}$ In another similar study in Japan, ${ }^{20}$ women workers without stress reduction techniques were found to be at significantly higher risk for suicidal ideation. In this sense, we need to provide more careful financial support to the households with women primary income earners to prevent worsening of their mental health.

Globally, politicians and public health administrators have tried to make healthcare as accessible as possible. ${ }^{89}$ The problem of accessibility is likely induced by both economic and spatial problems. In Korea, the amount and quality of healthcare access have improved over the past 30 years through rapid expansion of national health insurance. However, because national reimbursement was low, fiscal asset security in the healthcare system could not be sustainable. Although this problem gradually improved, a global economic crisis in 2008 hindered the ability of patients to visit clinics because of decreased incomes and heavy out-of-pocket expenses, especially for the low socioeconomic class with chronic and severe diseases, generating tremendous medical expenses. ${ }^{21}$ In this sense, many researchers have tried to determine the causes and economic outcomes of EHEs rather than their effects on health. However, these kinds of economic stresses worsen mental health and induce depressive disorders, suicidal ideation and numbers of suicide attempts. ${ }^{10}{ }^{16}$ For example, there was a steep increase in the number of patients with MDD, suicidal ideation and suicide attempts immediately after the international economic crisis in 2008. ${ }^{17} 1822$ The prevalence of MDD increased from $3.3 \%$ of the general population in 2008 to $8.2 \%$ in 2011 , which is a statistically significant difference. In addition, suicidal ideation among men increased from $4.4 \%$ in 2008 to $7.1 \%$ in $2011 .^{23}$

Similarly to these previous studies on this topic, our results also revealed the strong association between financial burden of health and suicidal ideation. However, there were several limitations to this study.

First, we could not determine the causal relationship due to the cross-sectional nature of the study. To 
Table 3 Multivariate analysis, based on the presence of suicidal ideation during the past year among heads of households with the threshold of excessive health expenditure as $10 \%$ from total expenditure in household

\begin{tabular}{|c|c|c|c|c|c|c|c|c|}
\hline \multirow[b]{2}{*}{ Variables } & \multicolumn{4}{|c|}{ Model $1(-2 \log L=1056.60)$} & \multicolumn{4}{|c|}{ Model 2 (-2logL=1032.57) } \\
\hline & $\overline{\text { OR }}$ & \multicolumn{2}{|c|}{$95 \% \mathrm{Cl}$} & p Value & $\overline{\text { OR }}$ & \multicolumn{2}{|c|}{$95 \% \mathrm{Cl}$} & $p$ value \\
\hline \multicolumn{9}{|c|}{ Excessive health expenditure ${ }^{*}$ during the last 2 years } \\
\hline None & 1.00 & & & & 1.00 & & & \\
\hline 2011, remote & 1.32 & 0.74 & 2.36 & 0.347 & 1.29 & 0.71 & 2.32 & 0.405 \\
\hline 2012, recent & 2.03 & 1.23 & 3.35 & 0.006 & 1.91 & 1.16 & 3.15 & 0.012 \\
\hline 2011 and 2012 & 1.83 & 1.12 & 2.98 & 0.016 & 1.67 & 1.01 & 2.78 & 0.048 \\
\hline \multicolumn{9}{|c|}{ Level of individual primary income earner } \\
\hline \multicolumn{9}{|c|}{ Sex } \\
\hline Male & 1.00 & & & & 1.00 & & & \\
\hline Female & 0.94 & 0.51 & 1.71 & 0.832 & 0.83 & 0.45 & 1.54 & 0.559 \\
\hline \multicolumn{9}{|l|}{ Age, over 65} \\
\hline$<65$ years & 1.00 & 1.00 & 1.00 & & 1.00 & 1.00 & 1.00 & \\
\hline$>65$ years & 0.57 & 0.36 & 0.91 & 0.018 & 2.52 & 0.32 & 20.13 & 0.384 \\
\hline \multicolumn{9}{|l|}{ Education } \\
\hline Degree from elementary school & 0.60 & 0.31 & 1.15 & 0.124 & 0.53 & 0.27 & 1.06 & 0.073 \\
\hline Degree from middle school & 1.03 & 0.54 & 1.98 & 0.930 & 0.96 & 0.49 & 1.89 & 0.899 \\
\hline Degree from high school & 0.90 & 0.50 & 1.60 & 0.713 & 0.85 & 0.47 & 1.54 & 0.596 \\
\hline Degree from college & 1.00 & 1.00 & 1.00 & & 1.00 & 1.00 & 1.00 & \\
\hline \multicolumn{9}{|l|}{ The presence of a spouse } \\
\hline Presence & 1.00 & 1.00 & 1.00 & & 1.00 & 1.00 & 1.00 & \\
\hline Absence & 0.54 & 0.30 & 0.96 & 0.035 & 0.54 & 0.28 & 1.06 & 0.072 \\
\hline \multicolumn{9}{|l|}{ Perceived health status } \\
\hline Excellent & 1.00 & 1.00 & 1.00 & & 1.00 & 1.00 & 1.00 & \\
\hline Good & 1.30 & 0.74 & 2.26 & 0.363 & 1.20 & 0.69 & 2.11 & 0.520 \\
\hline Poor & 1.78 & 1.03 & 3.08 & 0.041 & 1.61 & 0.92 & 2.82 & 0.093 \\
\hline \multicolumn{9}{|l|}{ Depressive mood } \\
\hline Sum of CESD-11 & 1.29 & 1.24 & 1.35 & $<0.001$ & 1.28 & 1.23 & 1.34 & $<0.001$ \\
\hline \multicolumn{9}{|c|}{ Regular medication more than 3 monthst } \\
\hline Absence & 1.00 & & & & 1.00 & & & \\
\hline Presence & 1.22 & 0.71 & 2.10 & 0.473 & 1.22 & 0.70 & 2.11 & 0.481 \\
\hline$<25 \%$ (lowest) & & & & & 2.01 & 0.97 & 4.15 & 0.059 \\
\hline $25-50 \%$ & & & & & 1.58 & 0.81 & 3.10 & 0.181 \\
\hline $50-75 \%$ & & & & & 1.60 & 0.86 & 2.96 & 0.139 \\
\hline$>75 \%$ (highest) & & & & & 1.00 & 1.00 & 1.00 & \\
\hline \multicolumn{9}{|l|}{ Number of family members } \\
\hline One & & & & & 1.00 & 1.00 & 1.00 & \\
\hline Two & & & & & 1.14 & 0.63 & 2.06 & 0.666 \\
\hline Three & & & & & 1.06 & 0.50 & 2.25 & 0.888 \\
\hline Four or more & & & & & 0.86 & 0.37 & 2.01 & 0.735 \\
\hline \multicolumn{9}{|l|}{ Economically active family member* } \\
\hline None & & & & & 1.29 & 0.65 & 2.58 & 0.465 \\
\hline One & & & & & 0.87 & 0.49 & 1.54 & 0.642 \\
\hline Two or more & & & & & 1.00 & 1.00 & 1.00 & \\
\hline \multicolumn{9}{|c|}{ Disabled person among family membersł } \\
\hline Absence & & & & & 1.00 & 1.00 & 1.00 & \\
\hline Presence & & & & & 1.12 & 0.71 & 1.75 & 0.626 \\
\hline Aged over 65 , among family memb & & & & & & & & \\
\hline Absence & & & & & 1.00 & 1.00 & 1.00 & \\
\hline Presence & & & & & 0.16 & 0.02 & 1.24 & 0.079 \\
\hline
\end{tabular}

*The variable of 'Economically active family member' is defined as someone who worked regularly and earned a salary during the past 1 year. †'Regular medication of more than 3 months' indicated the presence of ongoing chronic diseases.

$\ddagger$ Disabled person means those who are officially qualified by doctors as being disabled using the standard of the national guideline.

CESD-11, Center for Epidemiological Studies Depression Scale. 

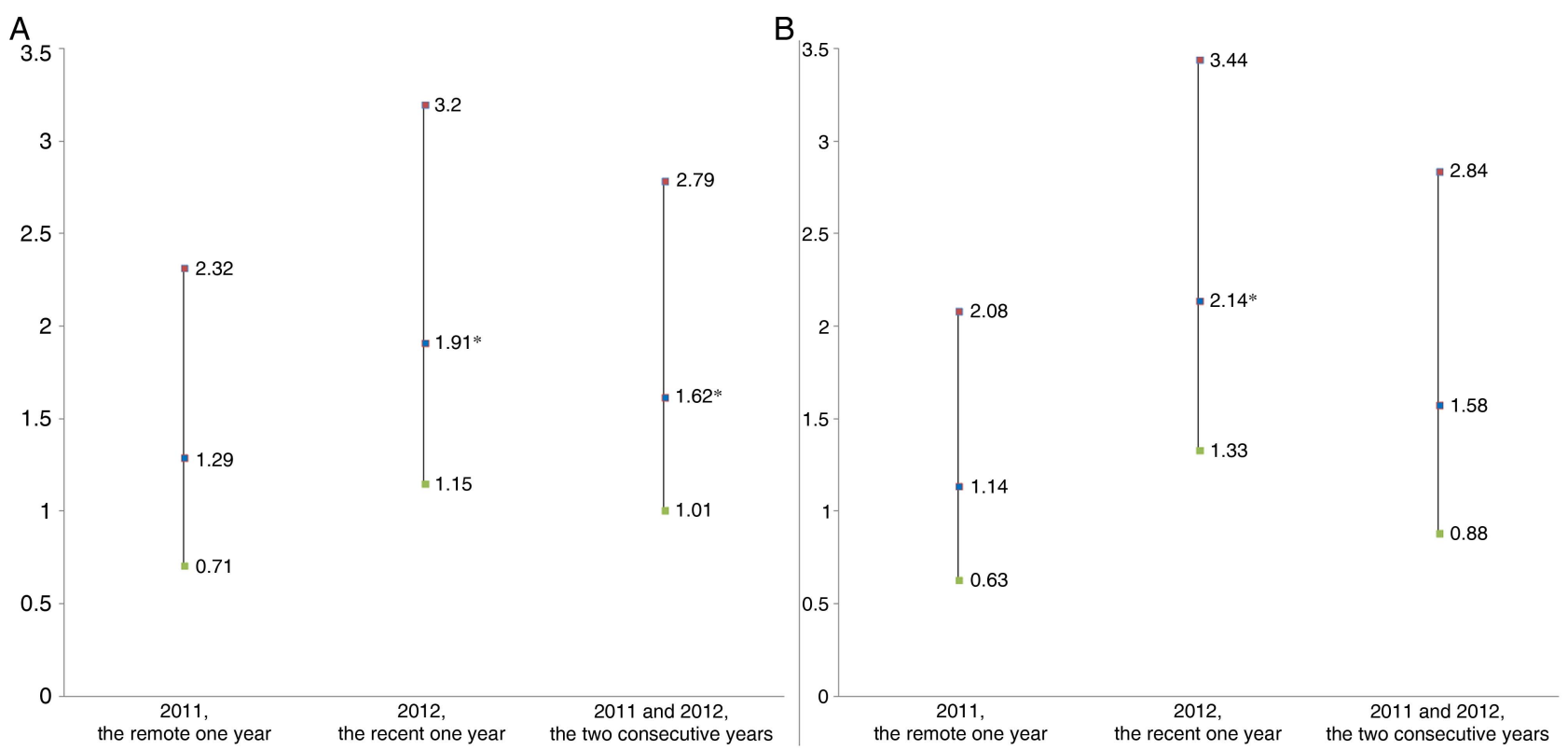

Figure 1 The primary income earners were more vulnerable to a high threshold of excessive health expenditure (EHE). In other words, when EHE was above $20 \%(B)$, compared to $10 \%(A)$, the OR for suicidal ideation with EHE in the recent 1 year was increased. *p Value $<0.05$

overcome this weakness, we divided the occurrences of EHE into four subgroups (none, recent, remote and both years) in an attempt to analyse temporal causality. Second, we used suicidal ideation, and not suicide attempt, as a dependent variable, because of the limited participants. However, suicidal ideation is still a powerful indicator to predict suicide attempts. ${ }^{24}$ According to one study in Korea, $84 \%$ of those who attempted suicide had previously seriously considered suicide within the last 2 years. ${ }^{25}$ Thus, even suicidal ideation is regarded as an important dependent variable for preventing the progress to suicidal attempt and suicide. Third, the number of cases of suicidal ideation may have been too small to determine all associations. Although we observed some statistical trends among independent variables for income level and temporal factors of EHEs, these trends did not reach statistical significance. One reason may be that the KoWePS study included investigations on mental health and suicide only since 2011, regardless of its initiation in 2006. Hence, we could not obtain more data for analysis. Fourth, we excluded other family members except for the primary income earner in households. Since family members under 19 years of age did not answer the CESD-11 scale, we could not adjust the depressive symptoms, which are some of the most important factors related to suicidal ideation. Fifth, we did not know what kinds of diagnosis categories, including mental and physical illness, were most significant to the occurrence of EHE. Although a few researchers studied the attributable medical conditions, ${ }^{15} 26$ their range was wide, and participants were defined as those with chronic diseases or as disabled. In this sense, further study is needed to investigate the disease specifically targeted to policy on EHE.

Despite such limitations, this study has several strengths, as follows.

Table 4 The adjusted ORs for suicidal ideation among the participants whose CESD-11 score is 16 or over, according to the various settings of thresholds of EHE

\begin{tabular}{|c|c|c|c|c|c|c|c|c|}
\hline & \multicolumn{4}{|c|}{ EHE > $>10 \%$} & \multicolumn{4}{|c|}{ EHE $>20 \%$} \\
\hline & OR & $95 \% \mathrm{Cl}$ & & p Value & OR & $95 \% \mathrm{Cl}$ & & p Value \\
\hline \multicolumn{9}{|c|}{ EHE during the past 2 years } \\
\hline None & 1.00 & & & & 1.00 & & & \\
\hline 2011, remote & 1.28 & 0.72 & 2.28 & 0.397 & 1.19 & 0.66 & 2.13 & 0.571 \\
\hline 2012 , recent & 1.98 & 1.21 & 3.22 & 0.006 & 2.46 & 1.57 & 3.85 & $<0.001$ \\
\hline 2011 and 2012 & 1.86 & 1.15 & 3.02 & 0.012 & 1.89 & 1.08 & 3.31 & 0.026 \\
\hline
\end{tabular}

We adjusted all the individual and household characteristics including sex, age, education, the presence of spouse, perceived health status, regular medication, income level, number of family members, the number of economically active family members, the presence of disabled in the family and the presence of those aged over 65 years in the family.

CESD-11, Center for Epidemiological Studies Depression Scale.

'EHE' is excessive health expenditure, which is the proportion of health cost in the disposable income of the household. 
First, this study used national open access data representing the Republic of Korea. Through this welldesigned panel survey, this study had high external validity and is able to be expanded in the future. Furthermore, this national data could be compared with data in other countries such as Japan and the Scandinavian countries, ${ }^{11}$ which have reduced suicidal mortality rates dramatically. Second, to the best of our knowledge, this is the first study on the relationship between EHE and suicidal ideation in Korea. Thus, it could draw the attention of other researchers and policy makers to the economic burden for health as an attributable factor to suicidal ideation.

Third, it is able to minimise the health disparity in society through the subsidies to EHE. Since EHE hinders the access to healthcare system, solving this problem could improve the basic human right for health and overall quality of public health. Korea has already started to provide subsidies for families with EHE in 2014, future studies could investigate the impact this support has had.

In summary, we still need to perform further investigation using a longitudinal study design with a larger population. Through accumulating these Korean data and following the trend of policy implication, we will coherently report the effect of the policy for EHE. However, we should mention that EHE could be considered as an important factor for aggravating mental illness through this study. Furthermore, it could swell, so it is important to consider and deal with newly occurring EHEs to protect vulnerable primary income earners such as women.

\section{CONCLUSION}

This is the first study to examine an association between EHE and suicidal ideation among primary income earners. For this group, a more severe depressive mood is associated with suicidal ideation. Furthermore, recent and greater EHE might increase suicidal ideation, especially in women. In conclusion, we suggest that in order to prevent suicidal ideation and to improve the mental health of individuals, especially for primary income earners in households, recent household EHE might be considered as an important factor. Furthermore, we hope that health policymakers will also take these results into account for the national financial support programme for EHEs in Korea, and develop immediate intervention after the onset of EHEs.

\section{Author affiliations}

${ }^{1}$ Department of Public Health, Graduate School, Yonsei University, Seoul, Republic of Korea

${ }^{2}$ Institute of Health Services Research, College of Medicine, Yonsei University, Seoul, Republic of Korea

${ }^{3}$ Department of Preventive Medicine, College of Medicine, Yonsei University, Seoul, Republic of Korea

${ }^{4}$ Department of Hospital Management, Graduate School of Public Health, Yonsei University, Seoul, Republic of Korea

${ }^{5}$ Department of Economics, College of Arts and Sciences, University of Washington, Seattle, Washington, USA
Acknowledgements We thank Biosciencewriters for checking and correcting the English in this manuscript.

Contributors JS and JWC designed the study and wrote the paper. YC and THI carried out the statistical analysis and provided important comments for this study. S-iJ and SGL were responsible for the statistical design. E-CP directed the study as corresponding author.

Funding This research received no specific grant from any funding agency in the public, commercial or not-for-profit sectors.

Competing interests None declared.

Ethics approval IRB of Graduate School of Public Health in Yonsei University. Provenance and peer review Not commissioned; externally peer reviewed.

Data sharing statement As we used public and national open data, we are willing to share our data and results. They are available on 'http://www. koweps.re.kr'. Extra data can be accessed via the Dryad data repository at http://datadryad.org/ with the doi:10.5061/dryad.j01v0

Open Access This is an Open Access article distributed in accordance with the Creative Commons Attribution Non Commercial (CC BY-NC 4.0) license, which permits others to distribute, remix, adapt, build upon this work noncommercially, and license their derivative works on different terms, provided the original work is properly cited and the use is non-commercial. See: http:// creativecommons.org/licenses/by-nc/4.0/

\section{REFERENCES}

1. Statistics Korea. National Health Statistics. http://kosis.kr/statHtml/ statHtml.do?orgld=101\&tblld=DT_1B34E01\&vw_cd=\&list

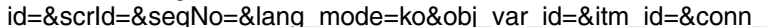
path $=\mathrm{E} 1$ (accessed Jun 2015).

2. Chan $\mathrm{CH}$, Caine ED, You S, et al. Suicide rates among working-age adults in South Korea before and after the 2008 economic crisis. $J$ Epidemiol Community Health 2014;68:246-52.

3. Xu K, Evans DB, Kawabata K, et al. Household catastrophic health expenditure: a multicountry analysis. Lancet 2003;362:111-17.

4. Brinda EM, Andres RA, Enemark U. Correlates of out-of-pocket and catastrophic health expenditures in Tanzania: results from a national household survey. BMC Int Health Hum Rights 2014;14:5.

5. Ilesanmi OS, Adebiyi AO, Fatiregun AA. National health insurance scheme: how protected are households in Oyo State, Nigeria from catastrophic health expenditure? Int $J$ Health Policy Manag 2014;2:175-80.

6. Li Y, Wu Q, Liu C, et al. Catastrophic health expenditure and rural household impoverishment in China: what role does the new cooperative health insurance scheme play? PLOS ONE 2014;9: e93253.

7. Ekman B. Catastrophic health payments and health insurance: some counterintuitive evidence from one low-income country. Health Policy 2007;83:304-13.

8. Kim S, Kwon S. The effect of extension of benefit coverage for cancer patients on health care utilization across different income groups in South Korea. Int $J$ Health Care Finance Econ 2014:14:161-77.

9. Li X, Shen JJ, Lu J, et al. Household catastrophic medical expenses in eastern China: determinants and policy implications. BMC Health Serv Res 2013:13:506

10. Ahnquist J, Wamala SP, Lindstrom M. Social determinants of health - a question of social or economic capital? Interaction effects of socioeconomic factors on health outcomes. Soc Sci Med 2012;74:930-9.

11. The Organisation for Economic Co-operation and Development (OECD). Health at a Glance 2013, OECD INDICATORS. http://www. oecd.org/health/health-systems/health-at-a-glance.htm

12. Baicker $\mathrm{K}$, Taubman $\mathrm{SL}$, Allen $\mathrm{HL}$, et al. The Oregon experimenteffects of Medicaid on clinical outcomes. N Engl J Med 2013;368:1713-22.

13. Patel V, Chisholm D, Kirkwood BR, et al. Prioritizing health problems in women in developing countries: comparing the financial burden of reproductive tract infections, anaemia and depressive disorders in a community survey in India. Trop Med Int Health 2007;12:130-9.

14. Kim Y, Yang B. Relationship between catastrophic health expenditures and household incomes and expenditure patterns in South Korea. Health Policy 2011;100:239-46. 
15. Choi JW, Cho KH, Choi Y, et al. Changes in economic status of households associated with catastrophic health expenditures for cancer in South Korea. Asian Pac J Cancer Prev 2014;15:2713-17.

16. Economou M, Peppou L, Fousketaki S, et al. [Economic crisis and mental health: effects on the prevalence of common mental disorders]. Psychiatrike Psychiatriki 2013;24:247-61.

17. Economou M, Madianos M, Peppou LE, et al. Cognitive social capital and mental illness during economic crisis: a nationwide population-based study in Greece. Soc Sci Med 2014;100:141-7.

18. Economou M, Madianos M, Peppou LE, et al. Suicidal ideation and reported suicide attempts in Greece during the economic crisis. World Psychiatry 2013;12:53-9.

19. Dalglish SL, Melchior M, Younes N, et al. Work characteristics and suicidal ideation in young adults in France. Soc Psychiatry Psychiatr Epidemiol 2015;50:613-20.

20. Yoon JH, Chang SJ. 0130 The combined effects of high emotiona demands and low job control at work on suicidal ideation in Korean sales and service workers. Occup Environ Med 2014;71(Suppl 1): A76-7.
21. Lee WY, Shaw I. The impact of out-of-pocket payments on health care inequity: the case of national health insurance in South Korea. Int J Environ Res Public Health 2014;11:7304-18.

22. Economou M, Madianos M, Peppou LE, et al. Major depression in the era of economic crisis: a replication of a cross-sectional study across Greece. J Affect Disord 2013;145:308-14.

23. Shafer AB. Meta-analysis of the factor structures of four depression questionnaires: Beck, CES-D, Hamilton, and Zung. J Clin Psychol 2006;62:123-46.

24. Rudd MD, Berman AL, Joiner TE Jr, et al. Warning signs for suicide: theory, research, and clinical applications. Suicide Life Threat Behav 2006;36:255-62.

25. Jeon HJ, Lee JY, Lee YM, et al. Unplanned versus planned suicide attempters, precipitants, methods, and an association with mental disorders in a Korea-based community sample. J Affect Disord 2010;127:274-80.

26. Choi JW, Choi JW, Kim JH, et al. Association between chronic disease and catastrophic health expenditure in Korea. BMC Health Serv Res 2015;15:26. 